\title{
Estresse e riscos ocupacionais em profissionais atuantes em um salão de beleza
}

\author{
Estrés y riesgos laborales en profesionales que trabajam en un salón de belleza
}

Stress and occupational risks in professionals working in a beauty salon

Natália Melo Lira da Costa
Universidade Federal de Roraima (UFRR), Boa Vista - RR/Brasil
ORCID: 0000-0002-3340-1201
E-mail: psiconataliacosta@gmail.com
Melissa Seelig Pamplona Barros
Universidade Federal de Santa Catarina (UFSC), Florianópolis - SC/Brasil
ORCID: 0000-0002-9146-2539
E-mail: melissa.seelig@ hotmail.com
Universidade Federal de Roraima (UFRR), Boa Vista - RR/Brasil
ORCID: 0000-0002-1292-5209
E-mail: fernandaax@ gmail.com

\section{Resumo}

Os salões de beleza podem ser definidos como espaços de convivência, com variadas experiências relacionadas à socialização. O objetivo do estudo foi identificar situações estressantes e riscos ocupacionais vivenciados por cabeleireiras e manicures que atuam em um salão de beleza no extremo norte do país. Tratou-se de um estudo de caráter qualitativo, no qual participaram da pesquisa 12 manicures e cabeleireiras. A coleta de dados ocorreu através da aplicação de um roteiro de entrevista semiestruturado, e a análise foi realizada à luz da Análise de Conteúdo de Bardin. Constatou-se que as situações estressantes relatadas pelas profissionais estão relacionadas com: a forma que suas clientes as tratam, ambiente quente, barulho e rivalidade entre colegas de trabalho. As profissionais reconhecem a presença de riscos ocupacionais em seus trabalhos, tais como: lidar com objetos cortantes, manusear e inalar produtos químicos, possibilidade de contrair doenças em geral, entre outros. Assim, é relevante investir em ações de educação e treinamento, para prevenir e minimizar o estresse e os riscos ocupacionais, com enfoque na saúde das clientes e na saúde das profissionais.

Palavras-chaves: Estresse; Riscos ocupacionais; Centros de embelezamento e estética.

\section{Resumen}

Los salones de belleza se pueden definir como espacios de vida, con variadas experiencias relacionadas con la socialización. El objetivo del estudio fue identificar situaciones estresantes y riesgos laborales que viven los peluqueros y manicuristas que trabajan en un salón de belleza en el extremo norte del país. Fue un estudio cualitativo, en el que participaron de la investigación 12 manicuristas y peluqueros. La recolección de datos se realizó mediante la aplicación de un guión de entrevista semiestructurado, y el análisis se llevó a cabo a la luz del Análisis de Contenido de Bardin. Se encontró que las situaciones estresantes reportadas por los profesionales están relacionadas con: la forma en que sus clientes los tratan, el ambiente caluroso, el ruido y la rivalidad entre compañeros de trabajo. Los profesionales reconocen la presencia de riesgos laborales en su trabajo, tales como: manejo de objetos punzantes, manipulación e inhalación de productos químicos, posibilidad de contraer enfermedades en general, entre otros. Por ello, es importante invertir en acciones de educación y formación, para prevenir y minimizar el estrés y los riesgos laborales, con foco en la salud de los clientes y la salud de los profesionales.

Palabras clave: Estrés; Riesgos laborales; Centros de belleza y estética.

\footnotetext{
Abstract

Beauty salons can be defined as living spaces with varied experiences related to socialization. The aim of the study was to identify stressful situations and occupational risks experienced by hairdressers and manicurists working in a beauty salon in the extreme north of the country. It was
} 
a qualitative study in which twelve manicurists and hairdressers participated in the research. Data collection occurred through the application of a semi-structured interview script and the analysis was performed in the light of Bardin's Content Analysis. It was found that the stressful situations reported by the profissionals are related to: the way their clientes treat them, hot environment, noise and rivalry between co-workers. The interviewees recognize the presence of occupational risks in their work, such as: dealing with sharp objects, handling and inhaling chemicals, the possibility of catching diseases in general, among others. Thus, it is relevant to invest in education and training actions to prevent and minimize stress and occupational risks focusing on the health of clientes and the health of profissionals.

Keywords: Stress; Occupational risks; Beauty and aesthetics centers.

\section{Introdução}

O Brasil ocupa o quarto lugar no ranking mundial de consumo de produtos relacionados à higiene pessoal, perfumaria, beleza e cosméticos representando $6,2 \%$ do consumo mundial de produtos deste setor, após os Estados Unidos, China e Japão. Como efeito da procura, em 2018 foram registrados 125,7 mil empregos diretos no setor, com uma alta de 4,3\% em comparação ao ano de 2017 (Associação Brasileira da Indústria de Higiene Pessoal, Perfumaria e Cosméticos - ABIHPEC, 2019). Frente a esses dados, nota-se que a indústria brasileira da beleza se encontra em expansão.

Os profissionais de salões de beleza são um segmento que têm acompanhado este crescimento. No Brasil, de acordo com pesquisa realizada pelo Euromonitor International para a Beauty Fair (2018), estimase que há por volta de 500 mil salões de beleza formais, sendo que os estabelecimentos informais contabilizam $48 \%$, mas o número de salões de beleza distribuídos pode ser maior, ultrapassando 1,1 milhão (Beauty Fair, 2018).

Serviços de cabeleireiros, manicures, depiladores, entre outros, estão sendo cada vez mais procurados, o que demonstra a crescente preocupação da população brasileira com a imagem e com a aparência. $\mathrm{O}$ aumento por esta demanda de serviço, em franco desenvolvimento, também impacta nos serviços prestados pelos salões de beleza e nos esforços em garantir a satisfação dos clientes em um contexto de aumento da competitividade e das exigências dos consumidores. Assim, essas exigências contemplam a preocupação em gerenciar esses empreendimentos nos critérios de qualidade e de agilidade, que constituem desafios contínuos nestas organizações (Martins, Venâncio, Fiates, Roman, \& Erdmann, 2014).

Os salões de beleza comumente são associados a noções de cosmética e estética corporal. No entanto, ao levar em conta as relações sociais que se estabelecem nestes espaços, Ferreira (2017) também os define como pontos de encontro relevantes para a sociabilidade, especialmente para o público feminino, visto que, apesar dos homens também consumirem práticas de beleza, este fenômeno ainda costuma ser maior entre as mulheres (Fontes, Borelli, \& Casotti, 2012). Quem frequenta os salões de beleza participa de fenômenos singulares, tais como troca de experiências e surgimento de amizades (Bouzón, 2010). Porém, a natureza destas relações também envolve a dimensão comercial, ao prestar um serviço ao cliente em troca de um retorno financeiro.

Sendo palco de relações humanas e trabalhistas, pressupõe-se que os salões de beleza, como qualquer outra organização de trabalho, estão vulneráveis à ocorrência de situações que podem se constituir como estressantes aos seus trabalhadores, os quais lidam diretamente com outras pessoas também imbuídas de suas particularidades. Considerando a natureza das funções de cabeleireiras e manicures, também se constata os riscos ocupacionais a que estas profissionais estão submetidas diariamente (Gallon, Bitencourt, Viana, \& Antonello, 2016; Lorenzini, 2012; Sarda, Líbano, Leite, \& Luz Neto, 2009). 
Diante desse cenário, este estudo teve como objetivo identificar situações estressantes e fatores de riscos ocupacionais vivenciados por cabeleireiras e manicures atuantes em um salão de beleza. Para além disso, pretendeu-se colaborar com o entendimento da realidade dessas profissões e sua relevância no cotidiano das pessoas.

\section{Salões de beleza: espaços de socialização para além dos cuidados estéticos}

"Os salões de beleza se apresentam como um ambiente particularmente rico em significados. (...) se destacam no contexto urbano pela singularidade do tipo de encontro que promovem e pela qualidade das relações e experiências que ali dentro tomam forma" (Bouzón, 2010, p. 14). Desse modo, pode-se dizer que o salão de beleza tem uma função que vai além das atividades específicas que são desenvolvidas em seu ambiente. É também um lugar de "sociabilidade muito distinta: revelase um misto de lazer e compartilhamento, de histórias pessoais, práticas de consumo" (Bouzón, 2010, p. 14).

Ao procurar um salão de beleza, além de receber os cuidados estéticos, o cliente pode estabelecer um vínculo com as pessoas que fazem parte daquele ambiente. Assim, por comparecer ao salão frequentemente, buscam em seus cabeleireiros e suas manicures uma amizade para desabafar, conversar sobre situações estressantes cotidianas, relaxar, revigorar a autoestima e dedicar um momento de cuidados para si, podendo sair deste ambiente satisfeitas, tanto com o que veem sua aparência física, o novo visual - quanto como se sentem, mais relaxadas e descansadas (Bouzón, 2010). Também, é possível considerar que os homens estão buscando estes serviços.

Assim, um profissional que trabalha no ramo da beleza tem muitas responsabilidades, principalmente por lidar diretamente com a autoestima dos clientes, na condição de satisfação ou de insatisfação. Quando sua manifestação é positiva, geralmente o indivíduo se sente confiante, competente e possuidor de valor pessoal. Essa autoestima é um importante indicador de saúde mental, por interferir em suas condições afetivas, sociais e psicológicas, impactando na qualidade de vida (Schultheisz \& Aprile, 2013) e também resultar em novas práticas e aprendizados (Gallon et al., 2016).

Desse modo, os salões de beleza podem ser definidos como espaços para trocar experiências, falar de si e dos outros, trocar notícias, cuidar da beleza, ser bastidor de importantes momentos da vida (formaturas e casamentos, por exemplo), descanso, socialização, construção de relações de afeto, espaço de convivência, esquecer os problemas (pessoais e do trabalho), "jogar" conversa fora, consumir tratamentos estéticos e ser experiência das interações e do lazer, local de "ponto de encontro" com as amigas, passar a semana "mais apresentável" para situações de lazer e de trabalho, sentir-se mais bonita nas interações sociais, relaxar e se divertir, momento para trabalhar acessando e-mails e fazendo ligações telefônicas (Ferreira, 2017), como também podem ser espaços de estresse e riscos ocupacionais, com repercussões na saúde.

\section{Estresse: conceituação e importância de seu estudo}

Limongi-França e Rodrigues (2005) descrevem o estresse sob duas vertentes: como processo e como estado. "O estresse como processo é a tensão diante de uma situação de desafio por ameaça ou conquista. $O$ estresse como estado é o resultado positivo (eutresse) ou negativo (distresse) da tensão realizada pela pessoa" (pp. 32-33). Tendo em vista tais conceitos, o estresse pode ser considerado positivo ou negativo. $\mathrm{O}$ estresse positivo (ou eustresse) geralmente é associado aos desafios da vida cotidiana, originados de situações excitantes e inesperadas (Mendes \& Leite, 2004), cujas doses não chegam a ser prejudiciais ao indivíduo que o experimenta. Já o estresse negativo (ou distresse) diz respeito às doses excessivas que superam a capacidade de adaptação, e são experimentadas como ameaça, repercutindo negativamente na saúde da pessoa. $\mathrm{O}$ estresse é um fenômeno 
recorrentemente associado ao trabalho sendo que "[...] é um estado de tensão ou ativação que, pela percepção repetida de ameaça (real ou imaginária), torna-se negativo ou crônico; ou seja, danoso ao próprio organismo [...]" (Zanelli \& Kanan, 2019, p. 73).

Wilhelm (2012) aponta que os eventos estressores podem ter fontes internas relacionadas à subjetividade, ao estilo de vida, às experiências, às características pessoais, dentre outros; já as fontes externas ao indivíduo constituem os acontecimentos relacionados às atividades de trabalho e de convivência, englobando situações como: mortes, acidentes, dificuldades financeiras, entre outras. Para a autora, cada indivíduo pode reagir de forma diferenciada diante de um mesmo estressor. Considerando a percepção e avaliação pelo indivíduo dos eventos considerados estressores, a simples presença de eventos estressantes, em determinado contexto no qual o indivíduo esteja inserido, não caracteriza um fenômeno de estresse. Assim, não são as situações em si que são importantes, mas como as pessoas as percebem.

Segundo Zanelli e Kanan (2019), o estresse constitui um dos riscos mais estudados, cada vez mais associado ao trabalho, relacionado a um estado de tensão ou de ativação diante de uma percepção, real ou imaginária, sobre uma ameaça, tornando-se negativo ou crônico, com danos ao organismo, como, por exemplo, aceleração cardíaca, hiperfuncionamento do organismo, falhas de memória, entre outras.

O estresse é uma resposta do organismo que provoca reações de níveis fisiológicos e psicológicos que podem produzir alterações de efeitos negativos e prejudicar a saúde do indivíduo. Pessoas que estão inseridas em ambientes estressantes tendem a apresentar maiores níveis de estresse, desse modo, o ambiente de trabalho, dependendo da sua organização e gestão de pessoas, pode colaborar com a elevação desses níveis de estresse em seus colaboradores, pois nesse local os profissionais estão expostos a riscos psicossociais que podem ter efeitos em nível físico, social e psicológico (Lemos, Carvalho, Mendes, \& Brys, 2021). O estresse ocupacional pode envolver reações fisiológicas, psicológicas e comportamentais em um processo de percepção subjetiva dos eventos estressores no ambiente de trabalho (PerezNebra, Carlotto \& Sticca, 2020).

De acordo com Tuten e Neidermeyer (2004, citado por Baptista, Soares, Raad \& Santos, 2019, p. 555), "a presença de eventos estressores no ambiente de trabalho exige do profissional um esforço para lidar com esse meio e suas cargas impostas". Isto o direciona a empreender esforços para conseguir o equilíbrio entre as demandas advindas do trabalho e os pessoais (Baptista et al., 2019). Quando o indivíduo não consegue fazer um manejo adequado das demandas do trabalho e pessoais, experimentando a sobrecarga psicológica e, consequentemente, o estresse, ele vivencia um mal-estar. Segundo Allemand, Schaffhuser e Martin (2015, citado por Baptista et al., 2019, p. 555), "quando os indivíduos experimentam alto nível de estressores de função no trabalho, eles têm dificuldade em cumprir suas atividades laborais e compromissos não relacionados, e tendem a apresentar sintomas depressivos", tornando cada vez mais importante o papel da organização no sentido de promover ações interventivas e preventivas, com enfoque na qualidade de vida e bem-estar dos trabalhadores.

O estresse é um fator inevitável, presente no cotidiano dos indivíduos e inerente à vida humana (Selye, 1965). Porém, quando associado ao trabalho e de forma negativa, pode trazer consequências desagradáveis que afetam a saúde (Lemos et al., 2021) e, consequentemente, o desempenho do trabalhador. Para o indivíduo, entre as consequências, podem estar falta de ânimo, falta de envolvimento com o trabalho, desgaste físico e mental, e em casos mais complexos síndrome de burnout. Para as organizações, entre os impactos, pode ocorrer absenteísmo, alta rotatividade, maior incidência de acidentes de trabalho, por exemplo (Fidelis, Zille \& Rezende, 2020). Por esse motivo, é 
imprescindível identificar os fatores que favorecem o desenvolvimento do distresse, especialmente em manicures e cabeleireiras que estão expostas em contextos de vulnerabilidades, inerentes às suas profissões, e necessitam desempenhar suas funções com qualidade, segurança e bem-estar.

\section{Os riscos ocupacionais a que estão sujeitos o cabeleireiro e a manicure}

Nos últimos anos, o mundo do trabalho tem sofrido intensas transformações. Silva e Tolfo (2012) chamam-nas de "metamorfoses", um fenômeno resultante “(...) das reconfigurações geopolíticas, sociais, econômicas, culturais e psicológicas, via de regra expressas na intensificação da globalização, criação acirrada de tecnologias, reestruturação da organização do trabalho e novas arquiteturas organizacionais" (p. 344). Novos arranjos trabalhistas surgiram e, junto com eles, novas formas contratuais que contribuem para a flexibilização das relações de trabalho (Silva \& Tolfo, 2012). O autoemprego, por exemplo, é um arranjo de trabalho que se configura como uma tendência atual dos profissionais no mercado de trabalho. É o caso das cabeleireiras e manicures do salão de beleza estudado, que trabalham sob a forma de prestação de serviços, sendo classificadas como MEI - Microempreendedoras.

O trabalho pode ser fonte de vários riscos à saúde do trabalhador, como, por exemplo, o estresse (Carlotto et al., 2018), e também os riscos ocupacionais a que estas microempreendedoras estão vulneráveis. Porém, é importante estabelecer a diferença entre as noções de risco e perigo. Em documento elaborado pela Organização Internacional do Trabalho [OIT] $(2011$, p. 1), o perigo é descrito como “(...) a propriedade intrínseca ou potencial de um produto, de um processo ou de uma situação nociva, que provocam efeitos adversos na saúde ou causa danos materiais". Como exemplo, destacam-se os produtos químicos que, essencialmente, têm um potencial nocivo para a saúde. Já o risco, “(...) é a possibilidade ou a probabilidade de que uma pessoa fique ferida ou sofra efeitos adversos na sua saúde, quando exposta a um perigo, ou que os bens se danifiquem ou se percam" (OIT, 2011, p. 1). Assim, o que configurará uma situação de risco é a exposição ao perigo, de forma imediata ou a longo prazo (OIT, 2011). A vivência do trabalho coloca o trabalhador em contato com diferentes fatores de risco. Particularmente, este estudo se propõe a focar os riscos ocupacionais, isto é, riscos que são inerentes à profíssão e intrínsecos à natureza da função, do exercício profissional e de fatores externos (Bessa, Almeida, Araújo \& Silva, 2010). Também, é possível destacar que os fatores psicossociais no ambiente de trabalho podem ser favoráveis quando proporcionam suporte, ajuda, proteção e fortalecimento aos trabalhadores com resultados positivos e podem ser desfavoráveis em situações ameaçadoras, perigosas e de risco (Zanelli \& Kanan, 2019).

Os riscos ocupacionais podem ser definidos como situações decorrentes do processo de trabalho com potencial para romper o equilíbrio físico, mental e social dos trabalhadores (Almeida, Torres \& Santos, 2012; Bessa et al., 2010), trazendo significativos impactos na saúde (Jacinto, Huck, Silva, \& Tolfo, 2020). Zanelli e Kanan $(2019$, p. 43) utilizam os termofatores de riscos psicossociais relacionados ao trabalho, como “(...) condições, circunstâncias ou acontecimentos que afetam os trabalhadores, os grupos, a própria organização e o contexto societário, em curto ou longo prazo, com maior ou menor severidade, de modo a potencializar a probabilidade de danos à saúde e segurança". No caso das profissionais da beleza e estética, como as cabeleireiras e manicures, estas estão expostas a inúmeros riscos ocupacionais causados por fatores químicos, físicos, biológicos, ergonômicos e psicossociais (Koerich et al., 2006), na interação com aspectos do trabalho, do trabalhador e do contexto social (Rodrigues \& Faiad, 2019).

De acordo com a Norma Regulamentadora 9 do Ministério do Trabalho e Emprego (Portaria $n^{\circ}$ 6.735, 2020), os riscos químicos dizem respeito à poeira, fumaça, gases, vapores e produtos químicos em geral. 
Os riscos físicos envolvem ruídos, vibrações, umidade, temperaturas, iluminação, entre outros. Os riscos biológicos englobam bactérias, fungos, protozoários, vírus, parasitas e bacilos. Já os riscos ergonômicos estão relacionados ao esforço físico intenso, levantamento de cargas pesadas, exigência de postura inadequada, entre outros (Mauro, Muzi, Guimarães \& Mauro, 2004; Zanelli \& Kanan, 2019). Considerando as mudanças no trabalho, nas organizações e em formas de adoecimento no trabalho, os riscos psicossociais foram incluídos como uma modalidade dos riscos ocupacionais (Almeida et al., 2012). Aspectos psicossociais associados ao trabalho estão relacionados a interação entre o trabalhador contemplando suas vivências, suas experiências e suas necessidades e o seu trabalho considerando seu ambiente, seu conteúdo de trabalho e suas tarefas (Jacinto et al., 2020). Entre os principais riscos psicossociais, encontram-se aqueles referentes à "aspectos da organização, gestão e processo de trabalho e às relações humanas" (Reis, Fernandes \& Gomes, 2010, p. 716).

Os riscos psicossociais retratam as percepções e experiências das profissionais relacionadas com as condições de trabalho (Jacinto et al., 2020). Considerando o público desta pesquisa, os possíveis riscos ocupacionais relacionados às atividades de manicures são: trabalhar em posição não confortável por longo tempo, ocasionando desconforto físico; não utilizar material descartável; lidar com objetos cortantes; aspirar o cheiro de acetona, de esmalte e formol; probabilidade de apresentar problemas visuais; não ter as vacinas em dia como prevenção; estar exposto à transmissão de infecções, como hepatite e vírus HIV (Gallon et al., 2016).

Em cabeleireiros, ocorre a exposição a diferentes substâncias químicas, como formaldeído (presente no processo de alisamento capilar) com reações na pele, mucosas, irritação ocular, diminuição da função pulmonar, entre outras, com níveis de exposição elevados, com efeito cancerígeno; ocorrência de cefaleia; náuseas; doenças de pele e do aparelho respiratório. Tais fatores podem diminuir a produtividade do trabalhador, até levá-lo a não poder mais desenvolver suas atividades laborais (Lorenzini, 2012).

Apesar dos serviços de cabeleireiros e manicures possuírem a finalidade de "embelezar" sua clientela, contribuindo para a saúde e bem-estar, é possível perceber que trabalhar em salões de beleza pode implicar em estar exposto a uma série de situações de riscos ocupacionais. Mesmo com o uso de EPIs (Equipamento de Proteção Individual), as vulnerabilidades destas profissões fazem-se presentes e são contínuas, sendo necessário conhecê-las para planejar ações, individuais e coletivas, de caráter preventivo e interventivo em seus processos de trabalho, implantar boas práticas favorecendo ambientes saudáveis, monitorar os riscos presentes e para promover saúde nos contextos de trabalho (Jacinto et al., 2020).

\section{Método}

Foi realizada uma pesquisa qualitativa, descritiva e exploratória, com o intuito de identificar fatores de riscos ocupacionais e situações estressantes, presentes no contexto de profissionais de um salão de beleza. A escolha pelo delineamento qualitativo deu-se em função da natureza e complexidade dos objetivos que nortearam esta investigação, no estudo das crenças, representações, realidades vividas e interpretações das pessoas de como sentem, pensam e vivem os processos sociais (Minayo, 2010).

Participaram da pesquisa 12 profissionais atuantes em um salão de beleza, localizado em uma cidade no extremo norte do Brasil, nas funções de manicures e de cabeleireiros. O projeto de pesquisa foi aprovado pelo Comitê de Ética em Pesquisa (CEP/UFRR), sendo o CAEE 06253218.2.0000.5302 e número do parecer 3.177.578. Foi aplicado individualmente um roteiro de entrevistas semiestruturado, em local apropriado, por apresentar as condições de não ter fluxo de pessoas, ruídos, interrupções e 
interferências, com iluminação satisfatória e ambiente ventilado.

A análise do material coletado foi qualitativa, com enfoque na Análise de Conteúdo, proposta por Bardin (2011), por meio da organização, sistematização, exploração e interpretação do material e, posteriormente, confrontação com a literatura da área.

\section{Resultados e discussão}

Tabela 1

Características Gerais das Participantes

\begin{tabular}{|c|c|c|c|c|c|}
\hline Participante & Idade & Sexo & Escolaridade & Função & $\begin{array}{l}\text { Anos de } \\
\text { atuação }\end{array}$ \\
\hline M. Maria flor & 26 & Feminino & Superior & Manicure & 5 \\
\hline M. Carmen & 29 & Feminino & $\begin{array}{c}\text { Superior } \\
\text { incompleto }\end{array}$ & Manicure & 10 \\
\hline M. Tamara & 31 & Feminino & Médio & Manicure & 4 \\
\hline M. Pérola & 41 & Feminino & $\begin{array}{c}\text { Superior } \\
\text { incompleto }\end{array}$ & Manicure & 11 \\
\hline M. Marina & 46 & Feminino & Médio & Manicure & 22 \\
\hline M. Luna & 46 & Feminino & Pós-graduada & Manicure & 7 \\
\hline C. Nice & 36 & Feminino & Superior & $\begin{array}{l}\text { Auxiliar de } \\
\text { cabeleireiro }\end{array}$ & 2 \\
\hline C. Dara & 40 & Feminino & Médio & Cabeleireira & 13 \\
\hline C. Rose & 32 & $\begin{array}{c}\text { Feminino } \\
\text { (transgênero) }\end{array}$ & $\begin{array}{c}\text { Superior } \\
\text { incompleto }\end{array}$ & Cabeleireira & 16 \\
\hline C. Dafne & 49 & Feminino & Médio & Cabeleireira & 15 \\
\hline C. Iasmin & 42 & Feminino & $\begin{array}{c}\text { Fundamental } \\
\text { incompleto }\end{array}$ & Cabeleireira & 12 \\
\hline C. Gabriela & 46 & Feminino & $\begin{array}{c}\text { Superior } \\
\text { incompleto }\end{array}$ & Cabeleireira & 20 \\
\hline
\end{tabular}

Nota. Tabela elaborada pelas pesquisadoras.

O grupo de participantes é do sexo feminino e os nomes apresentados são fictícios. As mulheres possuem características diversificadas quanto à idade e à escolaridade, demonstrando que não existem padrões para que se tornem profissionais na área da beleza. $\mathrm{O}$ fato de encontrarmos profissionais com longo tempo de atuação confirma que esse trabalho, ao contrário de alguns estereótipos, vai além de algo passageiro ou temporário; é o modo como muitas sobrevivem e sustentam suas famílias há anos. Assim, vão construindo suas carreiras profissionais.
Na época da coleta de dados, o salão de beleza contava com 57 funcionários, sendo 22 manicures, 18 cabeleireiros e os demais dividiam-se em: recepcionistas, estoquistas, podólogos, designers de unhas, fisioterapeutas para estética facial e corporal, designers de sobrancelhas e maquiadores. Os cabeleireiros e manicures trabalham através da prestação de serviço, sendo identificados como MEI Microempreendedor. As características gerais das participantes encontram-se expostas na Tabela 1. 
pentear e cuidar de todos os tipos de cabelos, além de fazer escovas, aplicação de cremes, químicas e tinturas. Já as manicures são responsáveis por tratar das mãos e pés dos clientes, aparando, polindo e esmaltando suas unhas.

Concluída esta breve contextualização das atividades desenvolvidas no trabalho, a seguir serão apresentadas as análises das narrativas das participantes, considerando duas dimensões: situações estressantes e riscos ocupacionais percebidos por estas profissionais.

\section{Situações de estresse no cotidiano de trabalho}

Nessa categoria, foram considerados os seguintes itens: se as participantes identificavam situações estressantes no seu ambiente de trabalho, exemplos das situações e se tais situações estressantes interferiam na execução de suas atividades laborais.

Observa-se nas falas a ocorrência de problemas, predominantemente, nas áreas das relações interpessoais, no relacionamento com as clientes, na forma de tratamento destas ("estressada"; falta de paciência; "descontar" nas profissionais, expressões que podem ser constatadas nas falas da M. Marina, M. Luna, M. Maria Flor, C. Tamara, C. Dara e C. Dafne); e no relacionamento entre as profissionais (fofocas e a colega atender sua cliente fixa), além do ambiente de trabalho lotado, que dificulta a locomoção dos carrinhos, e ao deslocar-se para receber a cliente; ser um trabalho com movimentos repetitivos, que pode ocasionar dor na coluna; barulho constante (secador de cabelo) com possibilidade de ocorrência de dor de cabeça; ser um ambiente quente, o que pode provocar desconforto e cansaço; grau de exigência das clientes; e preocupação em atender as expectativas por resultados satisfatórios relacionados à imagem.

Assim, o contato direto pode ser vivenciado de formas distintas no dia a dia, podendo provocar experiências positivas ou negativas. Desta maneira, a maioria das entrevistadas respondeu como fator estressante: "clientes estressadas, que costumam descontar na profissional", que acabam fazendo com que essas profissionais vivenciem experiências negativas e tenham seus limites de tolerância ultrapassados, provocando um mal-estar.

Considerando que a fonte de estresse pode ser qualquer evento estressor, tanto de origem interna como externa ao indivíduo (Wilhelm, 2012), os exemplos descritos são de situações de humilhação, impaciência da parte das clientes e de rebaixamento quando as colocam como pessoas que estão nessa profissão por não ter estudado, alimentando estereótipos.

\section{Eu tenho uma cliente que ninguém gosta de atender ela porque ela humilha muito as pessoas (...) ela disse assim: "É porque assim, eu estudo muito. Assim, vocês estudaram, mas vocês não estudaram como eu estudei (...) então são coisas desse tipo que, assim, se você não filtrar, é muito complicado. Ai entra mais uma vez naquilo: "tu não estudou" $e$ "se tu tivesses estudado". (M. Carmen).}

Outro aspecto citado foi "clientes que humilham", mencionado pela cabeleireira Nice, remetendo à humilhação e o sentimento de diminuição perante o outro, que se coloca como alguém superior às profissionais do salão de beleza. Nesse momento, aparece a questão da "falta de estudo", citada pela cliente, referindo-se ao suposto baixo nível de escolaridade para ter escolhido a profissão de cabeleireiro, o que é uma ideia errônea, conforme pode ser visto no Quadro 1 de caracterização das participantes, considerando que duas das entrevistadas possuem nível superior, quatro estão cursando e uma possui pós-graduação em nível de especialização.

A cabeleireira Nice também mencionou como estressante as humilhações e situações de rebaixamento: “(...) tenta humilhar, achando que porque ela chega, senta e está pagando, tem que ser feito da forma que ela quer (...)". A manicure Pérola destacou uma situação que a 
cliente não gostou do seu jeito de trabalhar: “(...) eu cheguei lá e fui fazer a unha dela e ela disse que não queria fazer a unha comigo, que procurasse outra pessoa porque ela não gostou do meu jeito de pegar na mão dela (...)”.

São situações delicadas que essas profissionais passam diariamente, que mexem de maneira significativa com o seu emocional e exigem delas um autocontrole para que possam desenvolver seu trabalho sem prejuízos. No entanto, passar pelas mesmas situações repetidas vezes pode gerar um estresse e desgaste e, consequentemente, um sofrimento, ao perceberem que sempre terão que dar um jeito para lidar com estas situações, pois dependem desse trabalho para sobreviver.

Por passarem muito tempo dividindo o mesmo ambiente, as entrevistadas também citaram como situações estressantes a fofoca e a rivalidade entre os colegas de trabalho, como pode ser visto na seguinte fala: “(...) coisas mesmo também do próprio salão. As vezes rivalidade entre os profissionais, fofoca, até porque a gente está lidando com seres humanos. Então todo mundo pensa de uma forma diferente (...)" (C. Rose).

Tal observação já é um estereótipo de salão de beleza, que é visto como um espaço coletivo de execução, não só de tarefas específicas, mas também pode ser considerado um espaço de sociabilidade, de lazer e de compartilhamento de histórias pessoais e desabafos (Bouzón, 2010). Ferreira (2017) traz essa mesma ideia quando afirma que os salões de beleza podem ser definidos como espaços para trocar experiências, falar de si mesmas e dos outros, trocar notícias, cuidar da beleza, descanso, socializar, construir relações de afeto, ser espaço de convivência, entre outras características. Em meio a tantas pessoas, pode ser que acabem compartilhando suas experiências de vida e que outros as escutem por estarem muito próximos fisicamente e não haver algum tipo de divisória no ambiente. Às vezes, pode ocorrer de a pessoa ao lado conhecer a pessoa a quem a outra está se referindo. Analisando a complexidade das interações humanas, Zanelli e Kanan (2019, p.
37) conceituam o termo "interações" como "(...) conjunto de relações de cunho psicológico (capacidades, necessidades, percepções e experiências) e social (ambiente de trabalho, condições organizacionais, condições pessoais externas ao trabalho, cultura)". Neste salão de beleza, são características da cultura trabalhar com uniforme, atender pontualmente no horário agendado e receber as clientes na recepção.

Quanto à rivalidade mencionada, sugere-se que seja devido ao fato de que, em geral, as profissionais têm suas clientes fixas e, muitas vezes, à longo prazo, gerando um vínculo e uma preferência em permanecer atendendo essa mesma cliente por já conhecêla e saber os seus gostos. Isto pode ocasionar um certo "ciúme", no caso da necessidade de um outro profissional atender a cliente do outro colega.

E por fim, também foi identificado como situação estressante o próprio ambiente físico de trabalho, o local onde são realizadas as atividades diárias, no que se refere à quantidade de pessoas, o barulho de equipamentos e principalmente o calor. A cabeleireira Rose exemplifica:

\section{(...) é um ambiente com muita gente, estressa, o barulho do secador estressa, principalmente quem tá na profissão há muitos anos, é... o calor... a gente tá numa cidade que é muito quente, então assim... o próprio ar condicionado, ele não dá conta, entendeu?}

Por ser um ambiente frequentado por muitas pessoas, pode ser propício que em algum momento haja uma situação que gere algum tipo de mal-estar, devido à superlotação, como ter que se locomover entre tantos carrinhos ou o difícil acesso para alcançar o material de trabalho. Sem mencionar o calor, que também é específico da região do extremo norte e se acentua em um ambiente lotado, gerando um desconforto. 
É possível destacar que, nas relações interpessoais, a queixa maior foi relacionada às clientes. Os cabeleireiros e manicures têm um certo tempo de convivência com seus clientes, gerando um vínculo de amizade. Porém, é possível que ocorram desentendimentos, muitas vezes causados pelas diferentes formas de pensar e de se expressar. Por isso, é importante o diálogo e a compreensão de ambas as partes, pois "os indivíduos são envolvidos pelas sensações, pelos sentimentos, e nem sempre pela racionalidade. E para se relacionar com os mesmos, é preciso um trabalho de compreensão, onde todos tenham flexibilidade para interagir uns com os outros" (Fonseca, Reis, Mesquita \& Alcantara, 2016, p. 7). Assim, quando o mal-estar não é resolvido, acaba gerando uma situação de estresse, como foi visto nas falas destacadas.

Cada ser humano lida de forma diferente diante das situações expostas. Neste sentido, algumas participantes responderam que não deixam que a situação de estresse tenha alguma consequência em sua rotina de trabalho e no seu modo de trabalhar, demonstrando que seu abalo poderia fazê-la não render. Como na fala da manicure Luna:

Pra mim não, porque é estressante, mas eu me sinto uma pessoa bem resolvida, em termos de trabalho, em termos de familia, sabe? Sei o que eu quero, sei até onde eu posso ir, sei o meu lugar, então pra mim não. Eu não costumo misturar trabalho com o relacionamento, com sentimento (...).

Isto, para elas, não pode acontecer, demonstrando ser um sentimento de que não se pode errar. É compreensível, uma vez que se está lidando com fregueses que contribuem para a manutenção de uma renda mensal.

Outras falas que se destacam são: “(...) não interfere no meu trabalho, porque eu não deixo (...)" (C. Rose) e “(...) acho que seria antiético eu passar adiante, então eu deixo pra lá, respiro e continuo (...)" (M. Marina). Aparentemente elas dominam a situação, porém, quando a pessoa acaba reprimindo suas emoções por medo de perder o emprego, por exemplo, pode adoecer. Pode ocorrer também o caso de não conseguirem enxergar as determinadas situações como algo que possa trazer algum malefício e ignorá-las, adotando comportamentos de fuga, negação ou esquiva, frente às situações estressoras. Estes comportamentos são tipos de estratégias de enfrentamento amplamente estudadas por Lazarus e Folkman (1984).

Por outro lado, a maioria das entrevistadas concordam quanto à presença de uma possível interferência em seu rendimento, o que pode ser observado na seguinte fala:
É... depois de uma situação dessa, a próxima cliente que você vai atender, você vai tá nervosa, vai tá desequilibrada emocionalmente, então vai ser difícil de atender essa próxima cliente, mesmo que seja uma pessoa maravilhosa, porque você tá com seu emocional abalado. (C. Gabriela).

Elas reconhecem que, depois de uma situação estressante, podem ficar abaladas emocionalmente, ficar chateadas com a situação e levar involuntariamente para a próxima cliente o que estão sentindo, por mais que se esforcem para não o fazer, como pode ser observado no trecho a seguir:

(...) eu costumo dizer pras meninas: "se não deu certo o primeiro horário, vai pra casa. Vai pra casa, descansa, relaxa pra começar de novo", porque parece que desanda assim completamente. Se você não parar, não focar no que tá fazendo (...). (C. Dara).

Apesar de serem vivenciadas de formas diferentes por cada pessoa, as consequências do estresse podem prejudicar a atuação do profissional. Quando os indivíduos experimentam um alto nível de estressores decorrentes do trabalho, eles se esforçam para lidar com essa situação, mas acabam tendo dificuldade em cumprir suas atividades laborais 
e externas ao ambiente de trabalho (Baptista et al., 2019).

Em geral, os impactos das situações de estresse citadas pelas manicures são a dificuldade de realizar de maneira excelente o serviço por estar com o emocional abalado e a repressão de suas emoções, quando precisam fingir que está tudo bem, pois dependem desse trabalho para sobreviver. Ambos geram um sentimento de raiva e angústia e podem interferir no desenvolvimento da profissional, visto que ela não fica satisfeita com o serviço que está executando e pode até se sentir incapaz.

Desta forma, reflete-se sobre a participação da organização, no sentido de promover ações interventivas e preventivas com enfoque na qualidade de vida e bem-estar dos trabalhadores (Jacinto et al., 2020; Fidelis et al., 2020). Ações que envolvam o diálogo são fundamentais, tanto dos profissionais com a gestão, como entre si, buscando a valorização desses profissionais e fazendo com que se sintam bem em seu ambiente de trabalho. "Os indivíduos desejam se sentir importantes em suas funções/tarefas propostas a realizar, e necessitam que seus gestores e colegas de trabalho e a equipe compreenda seus esforços" (Fonseca et al., 2016, p. 9). Quando uma pessoa expõe o que sente, facilita a relação com o outro, a comunicação entre a equipe, e assim, os conflitos que surgem ficam mais fáceis de serem solucionados. Assim, entre as possíveis ações nas organizações estão discutir sobre as situações estressantes no ambiente de trabalho, buscar estratégias para minimizar as repercussões do estresse, analisar como melhorar as condições de trabalho (Fidelis et al., 2020) e avaliar fatores de risco psicossocial no trabalho, oferecer suporte, fatores de proteção psicossocial e intervenções promotoras de saúde (Jacinto et al., 2020) para minimizar a ocorrência de riscos ocupacionais.

\section{Riscos ocupacionais identificados pelas profissionais}

Nessa categoria, serão expostas as análises dos relatos das participantes sobre os principais riscos ocupacionais percebidos. No caso das manicures, a contaminação por material perfurocortante sobressai nas falas de cinco participantes (Carmen, Tamara, Marina, Luna e Maria Flor), em acordo com os achados de Gallon, Bitencourt, Viana e Antonello (2016). Uma delas afirmou ter consciência de que deve ter o devido cuidado no manuseio do seu instrumento de trabalho e afirma que os materiais são devidamente esterilizados.

\section{(...) a gente trabalha com material perfurocortante, a gente pode se contaminar, por isso que tem toda uma questão. Na nossa higiene, na nossa segurança e tudo, e isso é muito sério. Pelo menos aqui com a gente, é muito sério e a vigilância sanitária bate muito em cima, então isso é um risco pra gente. E se eu não cuidar, eu vou ser diretamente afetada (M. Carmen).}

O manuseio de equipamentos cortantes é indicado como um risco na profissão de manicures, conforme mostram os trechos que se seguem:

(...) nós temos alguns riscos com relação à segurança mesmo... vamos falar assim... por exemplo... (...) se machucar, sabe? Com a unha da cliente... a cliente supostamente tem hepatite ou algo a mais, então a gente realmente corre esse risco. Mas assim, a gente toma as vacinas direitinho. Mas tem o vírus HIV também! Então... a gente realmente trabalha numa área de risco, como todo mundo trabalha... (...) o seu alicate estar esterilizado, você não se machucar, não machucar a cliente também. (M. Luna).

Aqui, no caso, não teria, porque temos... o nosso material é todo... o que poderia ser de risco seriam as contaminações, de hepatite, alguma coisa..., mas não tem isso, porque pela parte do material esterilizado, não tem como. Mas dizem que por esmalte ainda consegue transmitir, ai algumas clientes traz o seu próprio esmalte. 
Porque aqui não tem como tu usar um esmalte só numa cliente pra sempre, então cada uma traz o seu quando acha que tem risco, que tem medo de pegar alguma coisa por esmalte. Mas por conta de alicate, essas coisas assim, não tem como. É tudo bem esterilizado, descartável as coisinhas que é pra ser descartável, então a gente tem todo esse cuidado pra que nada disso aconteça. (M. Maria Flor).

O depoimento acima, de Maria Flor, evidencia a ocorrência de dois fenômenos. $\mathrm{O}$ primeiro diz respeito aos riscos ocupacionais, que orientam para práticas de cuidado e aperfeiçoamento do serviço prestado, como o fato de clientes trazerem seus próprios esmaltes e a preocupação da manicure com a esterilização e descartabilidade dos materiais. $\mathrm{O}$ segundo fenômeno, entendido como interligado ao primeiro, provoca este sentimento de segurança e bem-estar da trabalhadora diante das medidas protetivas de suas clientes e medidas autoprotetivas.

Neste caminho, chama a atenção a conscientização das trabalhadoras dos riscos em seus processos de trabalho, gerando saberes voltados para práticas seguras.

(...) agora a gente, no curso que a nossa instrutora deu, ela falou pra gente: "gente vocês não fiquem sem luvas, sem toca, sem até protetor intimo". A gente tem que usar, porque ela disse que foi feita uma pesquisa com ginecologistas e eles falaram que a maioria das pacientes que procuram eles é que tão com inflamação, com isso, com aquilo... é manicure, entendeu? E assim, ela no curso, ela falou muito isso aí, "vocês sempre procurem tá usando protetor íntimo". (M. Pérola).

A manicure Pérola destacou que algumas clientes podem ter fungos nas unhas e não mencionar, ou às vezes nem saber que tem. Este pó, proveniente das unhas contaminadas por fungos, ao cair nas roupas das manicures, pode entrar em contato com determinadas regiões corporais. Este é um dos motivos pelos quais elas são orientadas a usar devidamente os EPIs (Equipamentos de Proteção Individual), que são materiais voltados para a segurança e proteção dos trabalhadores, individualmente. Desde 2012, a Lei 12.592/12 tornou obrigatório o seguimento das normas da Agência Nacional de Vigilância Sanitária [ANVISA] que já haviam sido estabelecidas para proteção de cabeleireiros, manicures, esteticistas e clientes. Sendo algumas das instruções: trabalhadores de salões de beleza devem receber equipamentos de proteção (óculos, máscaras, luvas e jalecos) de acordo com as funções exercidas; os profissionais que realizam procedimentos, onde são utilizados materiais perfurocortantes, devem ser vacinados contra hepatite B e tétano, sem prejuízo de outras que forem necessárias; e equipamentos e instrumentos devem ser disponibilizados em quantidade suficiente para atender a demanda do estabelecimento, respeitando os prazos de limpeza, desinfecção e esterilização (ANVISA, 2009). É relevante destacar que ações de proteção são positivas e devem ser valorizadas (Zanelli \& Kanan, 2019).

Neste salão, foi percebido que há um cuidado por parte das manicures quanto à esterilização nos alicates de unha. No entanto, também devem ter cuidados com outros instrumentos, como por exemplo a esterilização da tesoura de unha. Algumas clientes levam seu próprio kit de manicure, o que poderia ser estimulado nos salões de beleza como medida de prevenção.

O nosso trabalho, ele diz que nós temos um... porque a gente trabalha com material químico dentro de um ambiente, então nós temos a possibilidade de ter muito é... câncer de esôfago, é... contrair doenças devido ao material cortante, porque a gente trabalha com material cortante, por isso nós temos todos os EPIs. Nós não trabalhamos... eu pelo menos não trabalho nem com a metade dos EPIs, mas que todo o aparato que o 
professional deve usar e corre risco, sim, porque a gente não sabe aquele cliente... que tipo de doença ele tem. Então, a gente termina correndo risco, por isso a gente sempre tem que tá atento a todas as precauções, a todos os cuidados (M. Marina).

Ressalta-se que as manicures, neste modelo de contrato de trabalho com o salão de beleza, são responsáveis por comprar e fazer a manutenção de seus próprios materiais de trabalho. A fala de Marina é intrigante, pois, apesar de ter ciência dos riscos, não há uma adesão completa de sua parte aos equipamentos de proteção individual. Isto abre margem para investigar quais fatores são determinantes para a adoção de comportamentos preventivos, considerando tantos os elementos internos (características individuais) como os externos (organizacionais, econômicos, culturais, políticos, entre outros).

Foi possível observar que neste salão, em geral, as profissionais não usam luvas e, portanto, isso pode ser um fator de risco, tendo em vista que as manicures atendem um número significativo de clientes por dia.

Em relação às cabeleireiras, estas também devem ter cuidados com seus instrumentos de trabalho, como, por exemplo, desinfetar escovas e toalhas. Sarda, Líbano, Leite e Luz Neto (2009) alertam sobre os principais riscos para esta categoria profissional: cortar-se com tesouras e navalhas, queimaduras por uso dos secadores, chapinhas e estufa. "Os agentes químicos podem agir no ser humano pelas seguintes vias de contaminação: inalação (é considerada a principal via de intoxicação), absorção (tornase crítica quando se trata de produtos absorvidos pela pele, e ingestão (pode ocorrer de forma acidental)" (Sarda et al., 2009, p. 159).

A cabeleireira Dara caracterizou queimaduras como um risco da profissão, devido ao manuseio de secadores e chapinhas, conforme expõe Sarda et al. (2009). Assim como Rose, Dara também apontou o fato de trabalharem com objetos cortantes, como tesoura e navalha, riscos também encontrados por Sarda et al. (2009).

Gabriela, Dafne e Rose identificaram como um risco da profissão um procedimento mal feito nos cabelos das clientes, assinalado por Rose: "O risco que pode acontecer é uma química não dar certo, entendeu? E eu acho que é um risco mais pra cliente do que pra mim." A cabeleireira Dafne emitiu sua concordância quanto a isso:

(...) a gente tem muito cuidado com essa parte, porque (...) todo cabelo é um cabelo, então eu vou ter que... eu aprendi muito com a empresa que eu trabalho (...), que a gente trabalha muito com teste, porque a cliente vem com o cabelo, ela senta, ela te fala uma coisa. Só que tem que ser igual médico, tem que ir lá e comprovar, e não jogar diretamente a química, porque depois que ela senta lá, a responsabilidade é tua, e às vezes ela não entende de cabelo e nem de química. Quem tem que entender sou eu, então eu que tô ali, eu sou a médica. Eu tenho que dar um jeito e às vezes no teste a gente já vê.

O depoimento da cabeleireira Gabriela corrobora o de suas colegas de profissão:

O risco que há é o risco de danificar o cabelo, é... nós trabalhamos com química e a química mal utilizada ela danifica o cabelo, como em casos que a gente pega muito de cabelos extremamente danificado, quebrando, caindo. Então esse risco existe, sim...

Elas frisaram a importância do teste de mecha, que é o nome dado a um procedimento feito antes da aplicação de produtos químicos aos cabelos. Como o nome já diz, é um teste usado para avaliar se quem vai receber o produto tem algum tipo de alergia ou sensibilidade e também se os fios são resistentes aos procedimentos que serão realizados em todo cabelo. Tal cuidado 
constitui um exemplo de prevenção de risco ocupacional ao evitar que algo pior aconteça, tal como danificar o cabelo do cliente, gerando prejuízos para o consumidor, para a profissional e para o salão, no sentido de que podem ser onerados. Além do prejuízo financeiro, a profissional pode ser demitida por seu erro. E tanto ela como o salão podem ter suas reputações questionadas entre a freguesia, o que de maneira geral não é considerado bom, do ponto de vista comercial.

Esta atitude preventiva de fazer o teste de mecha, além de ser uma forma de a profissional se precaver de queixas e críticas negativas ao seu trabalho, também pode estar relacionada diretamente com a preocupação com o bem-estar da cliente e sua satisfação. Desse modo, ao estar lidando com a imagem da cliente e sua autoestima, as cabeleireiras se veem na responsabilidade de fazer um bom serviço, sempre cuidando e manuseando corretamente o cabelo.

A cabeleireira Nice disse não haver riscos que envolvam seu trabalho, justificando a inovação dos produtos utilizados atualmente, que já não são tão maléficos como eram antigamente, o que traz para ela uma maior segurança. Em contrapartida, as cabeleireiras Rose, Dafne, Gabriela e Iasmin mencionaram como risco a inalação constante de fumaça do secador e o contato com produtos químicos. Mesmo com a inovação dos produtos, para Dafne, a química ainda faz mal e por esse motivo, inclusive, ela prefere não trabalhar mais com os tipos de procedimentos que utilizem químicas. Em seu ponto de vista, mesmo diante das transformações tecnológicas desses instrumentos, ainda é possível identificar malefícios para a saúde. Seu raciocínio é compreensível, quando se considera que o formaldeído, também chamado de formol, é um componente que continua presente em diversos produtos de beleza, beleza, como tinturas, descolorantes e alisante de cabelos e em alguns salões de beleza é utilizado em valores superiores permitidos pela Anvisa (Instituto Nacional de Câncer, 2021).
No caso de Iasmin, ela citou uma consequência da inalação dos produtos químicos: “(...) a gente trabalha muito com as coisas assim de química, de realinhamento, que é uma coisa mais forte assim, né? No final do dia, a gente tá com a garganta dolorida, porque é muita fumaça do secador...". Este dado traz à tona o estudo de Lorenzini (2012), no qual afirma que, em cabeleireiros, a exposição a diferentes substâncias químicas podem trazer consequências ao aparelho respiratório.

A maior parte destas substâncias manipuladas por cabeleireiros em salões de beleza (o formol, por exemplo) são considerados alergênicos e cancerígenos (Lorenzini, 2012). É importante ressaltar o ambiente de vários riscos em que estas profissionais estão inseridas, com a exposição constante a produtos químicos, com reduzidas alternativas de prevenção.

Algumas profissionais revelaram ter ações de prevenção diante destes riscos, como por exemplo, ter cuidado com o manuseio dos instrumentos; esterilizar os alicates; desinfetar escovas e toalhas; atenção à higienização pessoal e dos equipamentos; utilizar equipamentos de proteção (luvas e máscaras) e ter a carteira de vacinação em dia. Ações de proteção são positivas e devem ser valorizadas (Zanelli; Kanan, 2019) pois os riscos estão presentes nas diversas atividades laborais e podem ter efeitos em curto, médio ou longo prazo.

\section{Considerações finais}

Este estudo teve como objetivo identificar riscos ocupacionais e fatores estressantes vivenciados por cabeleireiras e manicures, atuantes em um salão de beleza. É possível concluir que os objetivos do estudo foram contemplados.

Foi possível identificar a existência de alguns eventos estressores oriundos destas profissões, em especial o relacionamento interpessoal entre as profissionais e as clientes. Nesse sentido, a gestão deve buscar, de forma contínua, a valorização do profissional, para 
que se sintam bem em seu ambiente de trabalho, que pode ocorrer através de ações que envolvam o diálogo, expressar seus sentimentos diante dos eventos estressores e o bem-estar das profissionais. Também é relevante a conscientização dos usuários de salões de beleza, quanto ao tratamento com o outro. Torna-se essencial destacar a importância de um olhar diferenciado e refletir sobre o real valor que essas profissionais têm.

Foi notória a existência de riscos ocupacionais voltados à ergonomia e biossegurança, que podem se agravar com a não utilização de alguns EPIs. Sendo assim, tal situação ainda é um desafio dentro do salão de beleza. Por neles serem desenvolvidas atividades que imprimem algum tipo de risco ao trabalhador que as executam, devem ser indispensáveis os usos dos equipamentos de segurança.

A relevância de oferecer um ambiente de trabalho seguro possibilita proporcionar que seus trabalhadores se sintam mais confortáveis para realizar seus serviços, com impactos na saúde destas profissionais, na saúde e satisfação dos clientes, e para a organização, com a provável fidelidade dos clientes, impactando nos benefícios financeiros.
Neste sentido, como exemplos de alternativas, os salões poderiam investir em ações de educação e treinamento em relação ao uso dos EPIs e incentivar seus profissionais a manterem a carteira de vacinação atualizada, considerando que essas ações são preventivas na saúde, tanto dos profissionais quanto dos clientes.

Quanto à exposição a componentes químicos potencialmente prejudiciais, é esperado que os salões sigam as recomendações da Agência Nacional de Vigilância Sanitária, no que tange à quantidade adequada de substâncias químicas para uso em cabelos. Trata-se de uma maneira de preserver, não só a saúde da equipe professional, como também dos clientes.

Destarte, esta pesquisa buscou contribuir para a produção de conhecimentos sobre os profissionais que atuam em salões de beleza, no sentido de possibilitar uma visão mais abrangente e humana de microempreendedoras que atuam no ramo estético. Sugere-se mais estudos voltados para esses profissionais, bem como trabalhadores autonômos e informais, suas relações de trabalho, estressores vivenciados em seus contextos de trabalho e riscos inerentes à sua atuação profissional.

\section{Referências}

Agência Nacional de Vigilância Sanitária [ANVISA]. (2009). Referência técnica para o funcionamento dos serviços de estética e embelezamentos em responsabilidade médica. Recuperado de https://repositorio.observatoriodocuidado.or $\mathrm{g} /$ handle/handle/2020? show=full

Agência Nacional de Vigilância Sanitária. (2018). Relatório - Coleta de informações junto às vigilâncias sanitárias locais sobre o uso irregular de formol em salões de beleza. Recuperado de http://portal.anvisa.gov.br/documents/2192 01/4340788/Relat $\%$ C3\%B3rio + Pesquisa $+\mathrm{F}$ ormol+2018+-
+ Vers $\% \mathrm{C} 3 \% \mathrm{~A} 3 \mathrm{o}+$ Final.pdf $/ 2 \mathrm{f} 7 \mathrm{f} 27 \mathrm{dd}-$

8eb3-4c2e-b2e3-92611ad3c55d

Almeida, L. G. N., Torres, S. C., \& Santos, C. M. F. dos. (2012). Riscos ocupacionais na atividade dos profissionais de saúde da atenção básica. Revista Enfermagem Contemporânea, 1(1), 142-154. doi: 10.17267/2317-3378rec.v1i1.51

Associação Brasileira da Indústria de Higiene Pessoal, Perfumaria e Cosméticos. (2019). Panorama do setor de higiene, perfumaria e cosméticos - 2019. Recuperado de https://abihpec.org.br/publicacao/panorama -do-setor-2019-2/

Baptista, M. N., Soares, T. F. P., Raad, A. J., \& Santos, L. M. (2019). Burnout, estresse, 
depressão e suporte laboral em professores universitários. Revista Psicologia Organizações e Trabalho, 19(1), 564-570. doi: 10.17652/rpot/2019.1.15417

Bardin, L. (2011). Análise de Conteúdo. Lisboa: Edições 70.

Beauty Fair. Panorama Salões de Beleza 2018. Recuperado de https://issuu.com/beautyfairnegocios/docs/p anoramasaloes

Bessa, M. E. P., Almeida, M. I. de, Araújo, M. F. M., \& Silva, M. J. da. (2010). Riscos ocupacionais do enfermeiro atuante na Estratégia Saúde da Família. Revista Enfermagem UERJ, 18(4), 644-649. Recuperado de https://www.researchgate.net/publication/3 17455617_Riscos_ocupacionais_do_enfer meiro_atuante_na_estrategia_saude_da_fa milia

Bouzón, N, P. (2010). Construindo identidades: um estudo etnográfico sobre manipulação da aparência em salões de beleza na cidade do Rio de Janeiro. (Tese de doutorado). Museu Nacional, Universidade Federal do Rio de Janeiro, Rio de Janeiro.

Carlotto, M. S., Câmara, S. G., Diehl, L., Ely, K., Freitas, I. M. de., \& Schneider, G. de A. (2018). Estressores ocupacionais e estratégias de enfrentamento. Revista Subjetividades, 18(1), 92-105. Recuperado de https://periodicos.unifor.br/rmes/article/vie w/6462/pdf

Ferreira, D. A. (2017). A estética e sociabilidade: o salão de beleza como ponto de encontro. CS Online - Revista Eletrônica de Ciências Sociais, 24(1), 274289. doi: 10.34019/1981-2140.2017.17531

Fidelis, J. F., Zille, L. P., \& Rezende, F.V. de. (2020). Estresse e trabalho: o drama dos gestores de pessoas nas organizações contemporâneas. Recape, 10 (3), 466-485.

Fonseca, L., Reis, R., Mesquita, K., \& Alcantara, A. O. (2016). Relacionamento interpessoal \& trabalho em equipe: impactos num ambiente organizacional. Anais do Congresso Nacional de Excelência em Gestão. Rio de Janeiro,
Brasil, 7. Recuperado de

https://www.inovarse.org/sites/default/files/ T16_215.pdf

Fontes, O. de A., Borelli, F. C., \& Casotti, L. M. (2012). Como ser homem e ser belo? Um estudo exploratório sobre a relação entre masculinidade e o consumo de beleza. REAd - Revista Eletrônica de Administração, 18(2), 400-432.

Recuperado de

https://www.scielo.br/pdf/read/v18n2/a05v 18n2.pdf

Gallon, S., Bitencourt, B. M., Viana, D. D., \& Antonello, C. S. (2016). Formas de aprendizagem e saberes no trabalho de manicures. Revista Pensamento Contemporâneo em Administração, 10(1), 96-112. doi: 10.12712/rpca.v10i1.655

Instituto Nacional de Câncer José Alencar Gomes da Silva. (2021). Ambiente, trabalho e câncer: aspectos epidemiológicos, toxicológicos e regulatórios. Instituto Nacional de Câncer José Alencar Gomes da Silva. Rio de Janeiro: INCA.

Jacinto, A., Huck, C. K., Silva, M. G. da. \& Tolfo, S. da. Fenômenos psicossociais relacionados ao trabalho: promovendo saúde e monitorando riscos (2020). In: Gestão de Pessoas e saúde mental do trabalhador: fundamentos e intervenções com base na psicologia. São Paulo, Vetor, 203-222.

Koerich, M. S., Sousa, F. G. M., Silva, C. R. L. D., Ferreira, L. A. P., Carraro, T. E., \& Pires, D. E. P. (2006). Biossegurança, risco e vulnerabilidade: reflexões para o processo de viver humano dos profissionais de saúde. On line Brazilian Journal of Nursing, 5(3). Recuperado de http://www.objnursing.uff.br/index.php/nur sing/article/view/564/129

Lazarus, R. S., Folkman, S. (1984). Stress, appraisal, and coping. New York, United States: Springer Publishing Company.

Lemos, I. S., Carvalho, J. V. S., Mendes, M. T. G., \& Brys, I. (2021). Mindfulness and relaxation: the effects of a program with university hospital workers. Estudos de 
Psicologia, 38, NA-NA. doi:

10.1590/1982-0275202138e190128

Limongi-França, A. C., \& Rodrigues, A. L. (2005). Stress \& Trabalho - Uma abordagem Psicossomática (4a. ed.). São Paulo: Atlas.

Lorenzini, S. (2012). Efeitos adversos da exposição ao formaldeído em cabeleireiros (Tese de Doutorado). Universidade Federal do Rio Grande do Sul, Porto Alegre.

Recuperado de https://www.lume.ufrgs.br/handle/10183/60 769

Martins, C., Venâncio, D. M., Fiates, G. G. S., Roman, D. J., \& Erdmann, R. H. (2014). Gestão de serviços em salões de beleza: do diagnóstico à melhoria de qualidade.

Gestão da Produção, Operações e Sistemas, 9(3), 79-93. doi: 10.15675/gepros.v9i3.1047

Mauro, M. Y. C, Muzi, C. D., Guimarães, R. M., \& Mauro, C. C. (2004). Riscos ocupacionais em saúde. Revista Enfermagem UERJ, 12(1), 338-345. Recuperado de https://www.researchgate.net/publication/3 42211512_Riscos_ocupacionais_em_saude Mendes, R. A., \& Leite, N. (2004). Ginástica laboral: princípios e aplicações práticas. Barueri, SP: Manole.

Minayo, M. C. de S. (2004). Pesquisa social: teoria, método e criatividade (23a. ed.). Petrópolis, RJ: Vozes.

Organização Internacional do Trabalho. (2011). Sistema de Gestão da Segurança e Saúde no trabalho: um instrumento para uma melhoria contínua. Bobadela: Ciência Gráfica.

Perez-Nebra, A. R., Carlotto, M. S. \& Sticca, M. G. (2020). Bem-estar e estresse ocupacional em contexto de distanciamento social. Orientações técnicas para o trabalho de psicólogos e psicólogas no contexto da crise COVID-19. Brasília: SBPOT.

Portaria $n^{\circ}$ 6.735, de 10 de março de 2020. Aprova a nova redação da Norma Regulamentadora no 09 - Avaliação e Controle das Exposições Ocupacionais a Agentes Físicos, Químicos e Biológicos. (Processo $n^{\circ} 19966.100181 / 2020-45$ ).
Recuperado de

https://www.in.gov.br/en/web/dou//portaria-n-6.735-de-10-de-marco-de-2020247539132

Reis, A. L. P. P. dos, Fernandes, S. R. P., \& Gomes, A. F. (2010). Estresse e fatores psicossociais. Psicologia: Ciência e Profissão, 30(4), 712-725. doi: 10.1590/S1414-98932010000400004

Rodrigues, C. M. Z., \& Faiad, C. (2019). Pesquisa sobre riscos psicossociais no trabalho: estudo bibliométrico da produção nacional de 2008 a 2017. Revista Psicologia: Organizações e Trabalho, 19(1), 571-579. doi: 10.17652/rpot/2019.1.15424

Sarda, L. K., Líbano, L. A., Leite, M. A. P., \& Luz Neto, P. N. da. (2009). Análise de riscos de um salão de beleza para verificação da conformidade com as normas. Caderno de Publicações Acadêmicas, 1(1), 157-160. Recuperado de https://periodicos.ifsc.edu.br/index.php/pub licacoes/article/view/57/21

Schultheisz, T. S. D. V., \& Aprile, M. R. (2013) Autoestima, conceitos correlatos e avaliação. Revista Equilíbrio Corporal e Saúde, 5(1), 36-48. doi: 10.17921/21769524.2013v5n1p\%25p

Selye, H. (1965). Stress: a tensão da vida. São Paulo: Ibrasa.

Silva, N., \& Tolfo, S. da R. (2012). Trabalho significativo e felicidade humana: explorando aproximações. Revista Psicologia: Organizações e Trabalho, 12(3), 341-354. Recuperado de http://pepsic.bvsalud.org/pdf/rpot/v12n3/v1 2n3a08.pdf

Wilhelm, F. A. (2012). Características das situações estressantes e estratégias de enfrentamento utilizadas por gestores universitários. (Tese de doutorado). Centro de Filosofia e Ciências Humanas, Universidade Federal de Santa Catarina, Florianópolis.

Zanelli, J. C., \& Kanan, L.A. (2019). Fatores de risco, proteção psicossocial e trabalho: organizações que emancipam ou que matam (2a. ed.). Lages: Eduniplac. 


\section{Dados sobre as autoras:}

- Natália Melo Lira da Costa: Graduada em Psicologia pela Universidade Federal de Roraima UFRR (2019). Experiência de estágio obrigatório com a abordagem Terapia Cognitivo Comportamental no atendimento com Dependente químico realizado no Serviço de Atendimento Psicológico da UFRR - SAP (2018). Experiência em estágio na área escolar na Escola Agrotécnica de Roraima - Eagro (2018-2019).

- Melissa Seelig Pamplona Barros: Graduada em Psicologia pela Universidade Federal de Roraima (UFRR). Mestranda em Psicologia pela Universidade Federal de Santa Catarina (UFSC) e bolsista pela Coordenação de Aperfeiçoamento de Pessoal de Nível Superior (CAPES). Membro do Núcleo de Estudos de Processos Psicossociais e de Saúde nas Organizações e no Trabalho (NEPPOT) e pesquisadora na área de concentração "Psicologia das Organizações e do Trabalho" na linha de pesquisa "Processos Psicossociais e de Saúde no Trabalho e nas Organizações". Tem interesse nos temas: trabalho, sentidos do trabalho, estresse, juventudes, universidade e vivências acadêmicas.

- Fernanda Ax Wilhelm: Possui graduação em Psicologia pela Universidade Regional de Blumenau (FURB). Pós-graduação em nível de especialização em Psicologia da Infância pela Universidade do Vale do Itajaí (UNIVALI). Mestrado em Psicologia pela Universidade Federal de Santa Catarina (UFSC). Doutorado em Psicologia pela Universidade Federal de Santa Catarina (UFSC). Pós-doutorado em andamento pela Universidade Federal de Santa Catarina (UFSC). Atualmente é docente, Classe D - Associado - nível 1, no curso de Psicologia, na Universidade Federal de Roraima (UFRR).

Declaração de Direito Autoral

A submissão de originais para este periódico implica na transferência, pelos autores, dos direitos de publicação impressa e digital. Os direitos autorais para os artigos publicados são do autor, com direitos do periódico sobre a primeira publicação. Os autores somente poderão utilizar os mesmos resultados em outras publicações indicando claramente este periódico como o meio da publicação original. Em virtude de sermos um periódico de acesso aberto, permite-se o uso gratuito dos artigos em aplicações educacionais e científicas desde que citada a fonte conforme a licença CC-BY da Creative Commons. 